\title{
Title: A Review on Plasticizers and Eco-Friendly Bioplasticizers: Biomass Sources and Market
}

\author{
Saabome Samuel Muobom (Main author) \\ Department of Chemical Engineering and Material \\ Science. \\ Sangmyung University \\ Seoul, South Korea \\ Abdul-Malik Saleem Umar \\ Department of Production and Quality Unit \\ Fanmilk Limited \\ Accra, Ghana
}

\begin{abstract}
Plasticizers are chemical additives added into polymers to influence desirable mechanical properties such as processability and ductility. These properties are a result of the association of plasticizer and polymer molecules under the theories of plasticization. This review analyzes, justifies and explore the use of bioplasticizers over phthalate based plasticizers. Owing to health concerns, depletion of crude resources and other factors, there is a gradual drift from traditional phthalate plasticizers to bioplasticizers in the plastic industry.

Bioplasticizers are derived mainly from biomass sources including agricultural products, it's by-products and waste. Regardless of the biomass source, ideal bioplasticizers are expected to be non-toxic, highly resistant to leaching, miscible, effective and relatively low in cost. Bioplasticizers such as epoxidized plant oils, cardanol, citrates and Isorbide esters are derived from further modifications of oils and triglyceride, starch and cellulose, citric acids and glycerol. By biomass sources, oils and triglycerides are obtained from oleaginous plants, starch and cellulose from cereals and citric acids from citrus. Citrate plasticizers have good miscibility, biodegradable, resistant to leaching and water and have legal use as additives. The demand for bioplasticizers is reported to increase from 887 kiltonnes in 2016 to 1900 kilotonnes in 2025 with a corresponding revenue of \$1124 Million dollars 2016 to \$2683.7 Million dollars by 2025.
\end{abstract}

Keywords: Plasticizers, bioplasticizers, biomass, citrates, market.

\subsection{INTRODUCTION}

Over the years, plasticizers have played a major role as a dominant additive in the plastic industry [1]. Its wide range of application can be seen in automobiles, packaging, consumer goods, pharmaceuticals and building and construction [2]. However, owing to environmental and health issues, the industry is gradually drifting from the traditional phthalate-based plasticizers to bio-based plasticizers [3]. In addition to this, bio-plasticizers have been experimented to give extended functionality over phthalatebased plasticizers. This augments to the popularity of bioplasticizers over traditional phthalate plasticizers.

Plasticizers are simply described as low molecular weight compounds added to polymers to lower glass temperature

\author{
Yoon Soongseok \\ Department of Chemical Engineering and Material \\ Science. \\ Sangmyung University \\ Seoul, South Korea \\ Adu-Poku Brolin \\ Department of Operations \\ Volta Aluminium Company Ltd \\ Accra, Ghana
}

and increase processability, workability and ductility [4]. Plasticizers are able to introduce new mechanical property changes when added into the matrix of the polymer as shown below in figure 1. The mechanism of action is termed plasticization. In addition, the mechanism of how the polymers are plasticized are described by theories which will be discussed in the later of this review.

However, with time and under certain conditions, the plasticizer can be lost and this poses environmental and health risk, hence the need for an eco-friendly and more improved plasticizers to be developed [5]. Efforts have been made to reduce the reduction of the migration of plasticizers in polymers through using more complex and higher molecular weight plasticizers which entangle in the polymer matrix to prevent migration. However, there is the downside of ineffective plasticization with this method. More research and efforts have also been made in the blend of plasticizers with nanoparticle $(\mathrm{CaCO} 3, \mathrm{SiO} 2)$ before introducing it into the polymer. This reduces the migration to some extent but however the amounts of plasticizers that still migrate out still pose health risks. This review spans on the overview of plasticizers, highlighting the demerits of traditionalphthalate base plasticizers and the need for eco-friendly biobased plasticizers. It also investigates into the different biomass sources and solicit for the best in potential biomass sources.

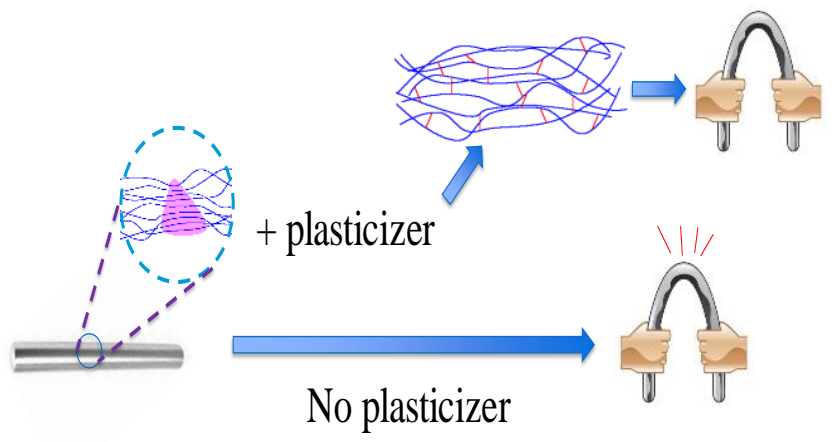

Figure 1: Illustration of the role of a plasticizer in a polymer matrix 


\subsection{Problem Statement}

When plasticizers are not chemically attached to polymer chains at certain conditions, it leaves the polymer through migration (Mass transfer) which leads to undesirable property changes in the polymer and consequent contamination of the surrounding medium [4].

When the polymer is used as food packaging materials, the migration leads to the plasticizer content diffusing into the food material in contact, this can cause food poisoning [6]. On the other hand, in polymers such as polyvinyl chloride (PVC) where the presence of the plasticizers are necessary for ductility and toughness properties, in such cases, when the plasticizer is being lost, the polymer loses and damages as well in respect to those properties [7]. Additionally, bulk of medical devices are made with PVC. Another adverse effect is seen when plasticizers are not chemically bound to the polymer matrix in a polyvinyl chloride (PVC) medical devices, it can be released into the solutions and blood products transported by these devices in pharmaceuticals [8]. These phenomena described are undesirable and hence the need for more improved plasticizers that will not leak and still introduce enhanced properties into polymers.

\subsection{Target group}

This review is relevant to stakeholders of the plastic industry which include producers, consumers, researchers, students and investors. This review will be very instrumental to new and fresh students, researchers and investors who do not have much insight of plasticizers as this review will slowly expand from the background of what plasticizers are, its mechanism and areas of application to the recent development in the plasticizer industry. Investors will also catch the glimpse of the future of plasticizers and bioplasticizers. Consumers and producers will be well informed on the dangers of using phthalate base plasticizers and as well as the merits of bio-plasticizers. Through this review, researchers can also explore the different biomass sources for producing bioplasticizers which could be employed for further research.

\subsection{BODY}

This section of the review will span on the overview of plasticizers, mechanism of action in plasticization, types of plasticizer and its application areas. We will also discuss phthalate-based plasticizers and its limitation. The synthesis and analysis of potential biomass sources for bioplasticizers will be discussed as well.

\subsection{Overview of plasticizers}

A plasticizer is defined according to IUPAC as a substance that is incorporated into a material to increase its flexibility, workability, or distensibility [9]. The principal effect a plasticizer influences is that, it changes the performance and characteristics of the plasticized product which makes it possible to use polymers in applications where the fore mentioned three characteristics are required [2].

\subsubsection{Plasticizer consumption}

Plasticizers are known to for their wide range of applications especially in the plastic industry. The demand for plasticizers is reported to be increasing and it is expected to scale approximately 9.75 million tonnes in 2024 [10]. The Zion report forecast the steady increase in demand from
2014 to 2020 estimating a 9,9605 kilotonnes of plasticizer volume by 2020 as shown in figure 2 .

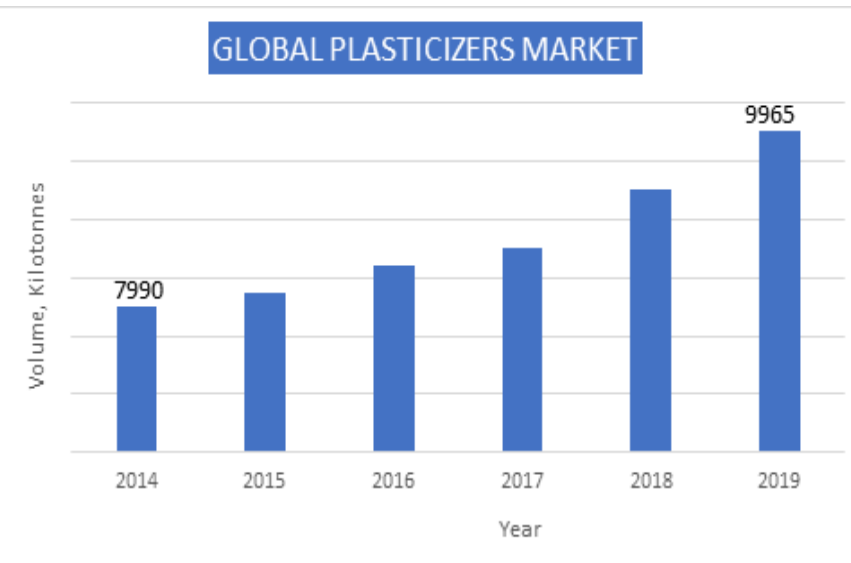

Figure 2: A graph showing the global plasticizer volume from 2014 2020. (Zion report, 2016)

Currently, of the many substances that are analyzed for their plasticizing properties, there are about 100 different plasticizers produced worldwide whilst only about 50 are considered commercially important [11]. There are wide ranges for their application. These include; automotive, packaging, consumer goods and building and construction [1]. Of these commercially produced, $90 \%$ are used in the production of Polyvinyl chloride [9]. Majority is also used in films and cables. In the analysis of the regional distribution profile of plasticizers as shown in figure 3, the Asia-Pacific region is seen to be the largest consumer. Recent reports claim China, Japan and South Korea to be the largest consumer of plasticizers and its related products.

\section{PLASTICIZER CONSUMPTION BY REGION}

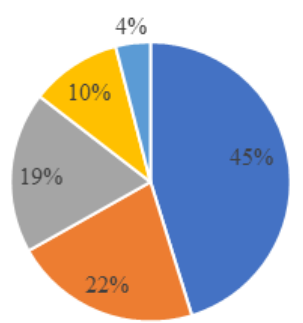

- Asia-Pacific " Europe " North America $\|$ South America " Middle East \& Africa

Figure 3: A graph showing the regional distributional of plasticizer consumption

\subsubsection{Theories of plasticization effect}

Plasticizers are able to introduce new mechanical property changes when added into the matrix of the polymer. This mechanism is termed plasticization. In the polymer, plasticization occurs by reducing the relative number of polymer-polymer contacts which decreases the rigidity of the three-dimensional rigid structure thereby allowing deformation of the polymer without rupture [12]. Consequently, plasticizers improve durability, processability, flexibility and in some cases the cost of polymers [13]. The mechanism of action can be explain on the Lubricity, gel and free volume theory [3]. 
According to the lubricating theory, the plasticizer molecules diffuse in the polymer and acts as shield reducing polymer interactions and this weaken the rigid structure enabling softens and flexibility [14]. The gel theory considers plasticizer joining to form weak three dimensional network with polymer chains therby making them weak to be overcome external applied stresses [15]. Relating to the free volume theory, adding more side chains and end groups to plasticizer modifies the polymer backbone which can move and rotate as shown in the figure (4) below [11]

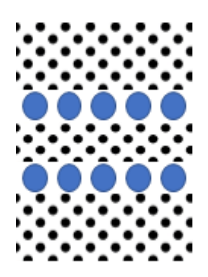

Lubricity theory

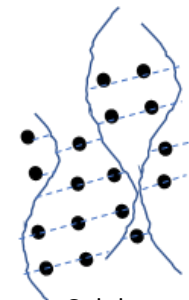

Gel theory

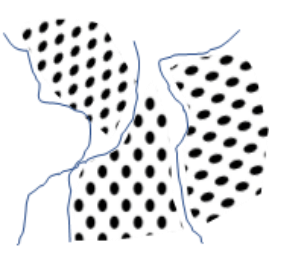

Free volume theory
- Polymer molecules $\quad$ Plasticizer molecules

Figure 4: Theories of plasticization

Plastcization can however be classified as internal or external [16]. Internal plasticization involves chemically modifying the polymer or monomer to increase flexibility whilst external plasticization imparts desired flexibility but does not chemical change by reaction with polymer. By this plasticizers in general could be describes as primary and secondary. Secondary adds more plasticization effects to primary plasticizers [9].

\subsection{Bio-based plasticizers}

In recent times, the use of petro-based plasticizers is being questioned because of toxicity and environmental health issues coming from plasticizer migration [17]. This relates for a large demand for new low toxic and low-migration natural-based plasticizers to replace petro-based ones.

For an ideal bio-based plasticizers, these properties expected are;

- Non-toxicity during metabolism

- Good miscibility with polymers

- High efficiency as normal plasticizers

- High resistance to leaching from polymer

- Relatively low cost.

\subsubsection{Biomass sources}

Biobased plasticizers can be obtained mainly from agricultural products, by products and waste [18]. This include a wide variety of agricultural resources: cereals, oleaginous plants, trees, fruits, and vegetables or their wastes as shown in the figure below. For instance, Vegetable oils from soybean, linseed, palm, castor bean are regarded as sources for good efficient bio-plasticizers. As a by-product from pulp and paper industry, Tall oil has been investigated to have a high potential for introducing plasticization effects. Also, starch and celulose obtained from cereals and tubers lead to numerous sugars and saccharides deriatives from which bio-plasticizers are produced [19]. Additionally, citric acid obtained from citrus fruits, sugarcane or beetroots is a very attractive biomass source leading to many different citrates and itaconates used as plasticizers. Additionaly, amino accids, waxes and lecithin have been studied as plasticizers [20].

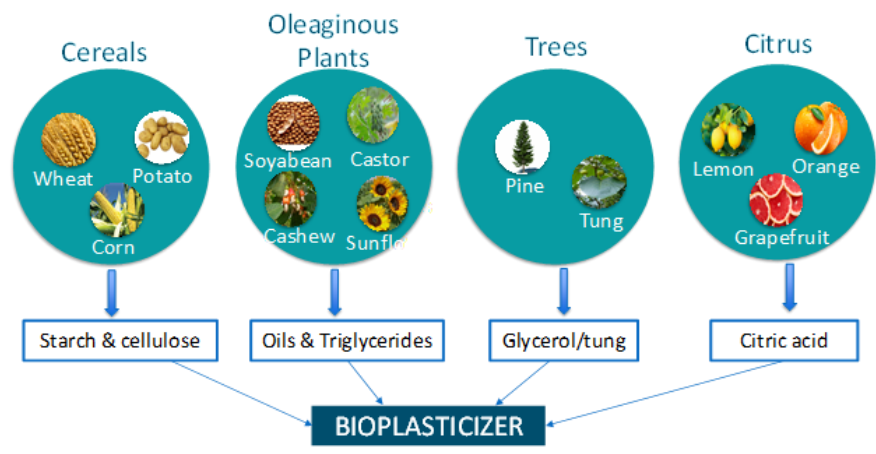

Figure 5: Biomass sources for bioplasticizers

\subsubsection{Vegetable oil as a biomass source}

Owing to the availability, biodegradability and low toxicity of vegetable oils, they represent a promising route to the production of bioplasticizers. They are mainly composed of triglycerides and triglycerols made up of glycerol and various fatty acids [21]. The triglycerides have a distinctive feature composed of two active sites: the ester group and double bond [22]. The ester group composed of glycerol and fatty acids can be esterified and used as plasticizers [23]. They are good potential for plasticizers as they react with polymer chains to bring compatibility. The double bond active site after going through epoxidation and acetylated can be used as plasticizers. The latter has seen many developments in the bio plasticizer industry in recent years. Notable among them are epoxidized soybean oil [24]. The epoxidized bio-plasticizers is advantageous on the fact, the epoxy groups are able to absorb and neutralize the hydrochloric acid released from PVC during thermal and light degradation thereby extending the life of PVC [25]. Other experimented ones include epoxidized olive oil, corn oil, cottonseed oil and sunflower oil [26] . Table 1 presents industrial bio-plasticizers used mainly in PLA and PVC made from vegetable oil.

Table 1: Industrial bio-plasticizers used in the Industry

\begin{tabular}{|l|l|l|l|}
\hline $\begin{array}{l}\text { Plasticizer } \\
\text { trade name }\end{array}$ & $\begin{array}{l}\text { Chemical } \\
\text { Name }\end{array}$ & Feedstock & $\begin{array}{l}\text { Bio-based } \\
\text { content }\end{array}$ \\
\hline $\begin{array}{l}\text { GrinstedV } \\
\text { SOFT-N-SAFE }\end{array}$ & $\begin{array}{l}\text { Acetylated } \\
\text { castor oil }\end{array}$ & Castor oil & $80 \%$ \\
\hline Kalflex® 14A & ESBO & $\begin{array}{l}\text { Soyabean } \\
\text { oil }\end{array}$ & $98 \%$ \\
\hline Nexo® E01 & $\begin{array}{l}\text { Methyl } \\
\text { epoxy } \\
\text { soyate }\end{array}$ & $\begin{array}{l}\text { Soyabean } \\
\text { oil }\end{array}$ & $95 \%$ \\
\hline Resiflex® K50 & $\begin{array}{l}\text { Amyl } \\
\text { expoxy } \\
\text { soyate }\end{array}$ & $\begin{array}{l}\text { Soyabean } \\
\text { oil }\end{array}$ & $100 \%$ \\
\hline DCS $®$ & $\begin{array}{l}\text { Di-capryl } \\
\text { sebacate }\end{array}$ & Castor oil & $100 \%$ \\
\hline PLS Green $₫ 9$ & $\begin{array}{l}\text { Nonyl } \\
\text { epoxy } \\
\text { soyate }\end{array}$ & $\begin{array}{l}\text { Soyabean } \\
\text { oil }\end{array}$ & $60 \%$ \\
\hline
\end{tabular}




\subsubsection{Starch and cellulose as plasticizers biomass sources}

Starch and cellulose are collectively called polysaccharides [27]. The former is mainly obtained from cereals and tubers whilst the latter are extracted from straws and cotton fibers. After hydrolysis of the polysaccharides, different monosaccharides are produced which further can lead to sugar alcohols. The sugar alcohols in mention here include glycerol, xylitol, just to mention but a few. Reports from further studies shows that glycerol and xylitol have better plasticizing effects on starch polymers [28].

Another derivative of glucose from hydrolysis of polysaccharides is isosorbide esters. These esters are biodegradable, less toxic, and thermally stable heterocyclic diol derived from glucose. It is obtained after double hydrogenation of sorbitol which is also obtained from the hydrogenation of glucose [26]. However, a major setback has been identified with this type of plasticizer to be hygroscopic by absorbing water into the polymer thereby swelling up the polymer.

\subsubsection{Biowaste and by-products as bio plasticizer biomass sources}

Waste and by products from many bio-processes have been tested as plasticizers on various polymers and materials. This include tannins, glycerol, sugar and cellulose bagasse, wood flour, rice bran and among others [22]. Tannins have been experimented as super plasticizers in cement and concrete mixes [29]. Sugar and cellulose bagasse were modified and used in plasticizing cellulose acetate [30]. Also, ester derivative from wood floor and rice ban have been tested as plasticizers and shown good results [31].

Another dominative biomass in the bio plasticizer industry is glycerol. Glycerol is defined simply as a polyol composed of three hydroxyl groups responsible for its water-solubility. It is obtained as a by-product from biodiesel synthesis [22]. It is commonly known for its application in the plasticization of starch polymers [32].

Cardanol is a particular vegetable oil that is obtained as by product from the distillation of cashew nut shell. Cardanol were initially analyzed and used for plasticization of soft PVC. However, the results showed partial miscibility feature with PVC. On the contrary, after epoxidation of the esterified compound showed good miscibility with PVC. The esterified cardanol was adjudged to be suitable as a secondary plasticizer whilst the epoxidized esterified cardanol cold be use as primary plasticizer [33]. Table 2 shows the comparison of common bioplasticizers

Table 2: Comparison of bioplasticizers and their biomass sources

\begin{tabular}{|c|c|c|c|}
\hline $\begin{array}{c}\text { Bio- } \\
\text { plasticizer }\end{array}$ & Source & Advantages & Disadvantages \\
\hline $\begin{array}{l}\text { Epoxidized } \\
\text { plant oils }\end{array}$ & $\begin{array}{c}\text { Soyabean oil. } \\
\text { Sunflower oil, } \\
\text { castor oil }\end{array}$ & $\begin{array}{c}\text { Readily } \\
\text { available, } \\
\text { Relatively low } \\
\text { cost, low } \\
\text { toxicity, good } \\
\text { secondary } \\
\text { plasticizers }\end{array}$ & $\begin{array}{l}\text { Relatively high } \\
\text { exudation, } \\
\text { relatively poor } \\
\text { miscibility }\end{array}$ \\
\hline
\end{tabular}

\begin{tabular}{|c|c|c|c|}
\hline $\begin{array}{c}\text { Isorbide } \\
\text { esters }\end{array}$ & Glucose (starch) & $\begin{array}{c}\text { Biodegradable, } \\
\text { non-toxic, } \\
\text { thermally stable }\end{array}$ & $\begin{array}{c}\text { Complex process } \\
\text { of production, } \\
\text { hygroscopic }\end{array}$ \\
\hline Cardanol & Cashew nut & $\begin{array}{c}\text { Good } \\
\text { miscibility, } \\
\text { Good secondary } \\
\text { plasticizer. }\end{array}$ & $\begin{array}{c}\text { Partial } \\
\text { miscibility with } \\
\text { PVC, PLA. }\end{array}$ \\
\hline Citrates & Citrus acid & $\begin{array}{c}\text { Biodegradable, } \\
\text { good miscibility, } \\
\text { non-toxic }\end{array}$ & $\begin{array}{c}\text { Relatively high } \\
\text { cost. }\end{array}$ \\
\hline
\end{tabular}

\subsubsection{Synthesis of bio plasticizer from the esterification of citric acid.}

Citrate plasticizers as they are collectively called, are tri or tetra esters obtained from the esterification of citrus acid. Citric acid is known to be obtained from citrus fruits, sugar cane and beetroots [34].

$\mathrm{Wu}$, Wang and Chen described citrate plasticizer as basically obtained by reaction of citric acid and ethanol in an esterification reaction as shown in equation 1. Among citrate esters, triethyl citrate and tributyl citrate are paramount of which the former is most dominant in the plasticizer industry [35]. Triethyl citrate is prepared from the esterification reaction of citric acid with bio-ethanol. Bioethanol can be obtained from the fermentation of all sugar bio-source including all polysaccharides based products [36].

\subsubsection{Triethyl acetate as a plasticizer}

Triethyl acetate is produced from the esterification of citric acid and ethyl alcohol as patented by $\mathrm{Wu}$, Wang and Chen. During esterification of the citric acid, the carboxyl groups in the citric acide are replaced by the ethyl groups from the ethanol forming the structure as shown in the figure 6 below [37]. In their patent, $\mathrm{Wu}$, wang and Chen reacted citric acid with ethyl alcohol using alkali as a catalyst in a reaction mixture ranging from $60{ }^{\circ} \mathrm{C}$ to $100{ }^{\circ} \mathrm{C}$. they also reported that triethyl citrate having good compatibility, high plasticizing efficiency, non-toxic, easily biodegradable and less volatile, light resistance and water resistance, shock resistance have a resin having no growth of fungi etc., and is an internationally recognized green plastic plasticizer widely used in food, medical products, cosmetics, daily necessities, children's toys and so on. Thus, the citrate compound is an excellent alternative to traditional plasticizer [38].

$$
\begin{array}{cccc}
\mathrm{C}_{6} \mathrm{H}_{8} \mathrm{O}_{7}+3 \mathrm{C}_{2} \mathrm{H}_{6} \mathrm{O} & \rightarrow & \mathrm{C}_{12} \mathrm{H}_{20} \mathrm{O}_{7}+3 \mathrm{H}_{2} \mathrm{O} \\
\text { Citric acid Ethanol } & \begin{array}{l}
\text { Triethyl Water } \\
\text { Citrate }
\end{array} &
\end{array}
$$

Equation 1: Esterification of citric acid and ethyl alcohol. 
<smiles>CCOC(=O)CC(O)(CC(=O)OCC)C(=O)OCC</smiles>

Figure 6: Chemical structure of triethyl acetate

Nandiwale also experimented citrate plasticizers by the synthesis of triethyl citrate from citric acid obtained from orange waste, an approach to adding value to agricultural waste. He developed an environmentally friendly catalytic process to produce triethyl citrate under optimized conditions in a closed bath system [39].

Jia reported that, when triethyl citrate is mixed with the polymer matrix of PVC in internal plasticization, it modifies the PVC material thereby exhibiting thermal stability, lower glass temperature and near zero migration [39]. Jan Gooch also reported the approved legal use of triethyl citrate. He reported that, triethyl citrate as enlisted in 21 CFR 184.1911 can be used food substance affirmed as Generally Recognized as Safe (GRAS) substance. This ingredient may be used in food related products with no limitation other than current good manufacturing practices. Also, it is enlisted in the Codex Alimentarius General Standard for Food Additives as a food additive [36].

\subsubsection{Future and market of bio-based plasticizers}

Bio based plasticizers have been designed to replace the traditional present phthalate-based plasticizers and as expected replacement in its application, market size and share as well. The bio plasticizer market is analyzed based on the type (Citrates, Epoxidized oils, succinic acids \& others), application (packaging materials, medical devices, consumer goods, wires and cables, building and construction) and region. According to Grandview research market report on bioplasticizers, the market of bio-plasticizers was forecasted $\$ 1124.3$ million by 2016 is expected to reach $\$ 1,1403$ million by 2020 and $\$ 2,6837$ by 2025 registering a cumulative average growth rate of $9.5 \%$ from 2015 to 2020 as shown in figure 6 [40].

\section{BIOPLASTICIZER MARKET BY PRODUCT: A CASE STUDYINTHE US (USD DOLLARS)}

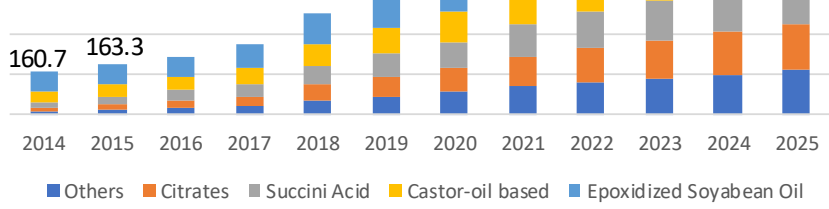

Figure 7: Global bioplasticizers market by worth and volume from 2016 2025
By region, the north America is reported to be a promising market bio-plasticizer. It is one of the largest markets for bio-plasticizers with a recorded market share of 36\% in 2014. This is owed to stringent rules from policy makers in that region [41]. Cerena reports claims that, non phthalates plasticizer demand is expected to increase at $3.3 \%$ yearly till about a volume of 2.3 million tonnes is realized occupying a total volume of $22 \%$ of world global plasticizers [42]. However, grand view research reports bioplasticizers at a volume of 887.3 kilo tonnes in 2016 and expected to rise at rate of $9.5 \%$ per annum to 1900 kilo tonnes by 2025 [1]. With citrate plasticizers having delicate applications in cosmetic, medical, pharmaceutical and food packaging, investing in the production of citrate plasticizers will be worthwhile in the near future [43]. Figure 7 shows the forecast of the growth of plasticizers worth according to type from 2014 to 2025 [1] .

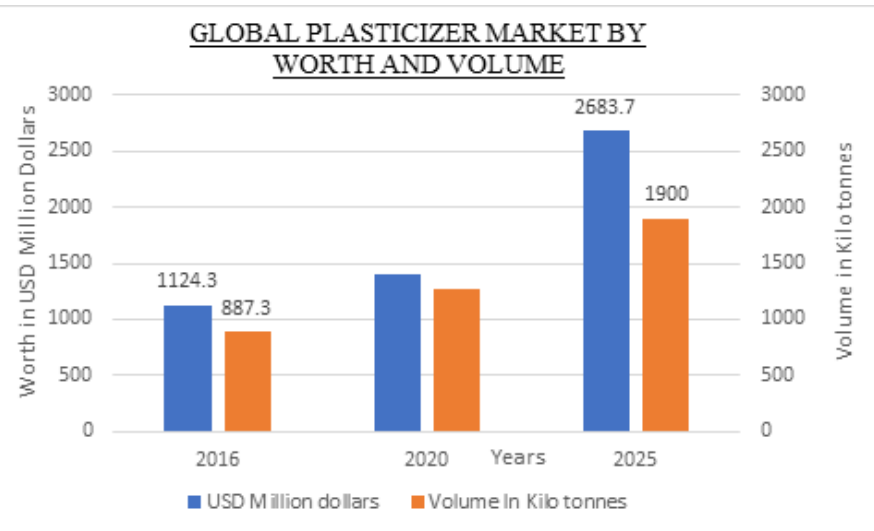

Figure 8: Bioplasticizer market revenue distribution by product: A case study in US

\subsection{CONCLUSION}

The review paper seeks to address the recent claims in the use of traditional petro based plasticizers and analyzes the potential of bio sources as a replacement. In the review, plasticizers were analyzed under types, application and regional distributing in consumption. The review also covered on general theories governing the action of plasticizers in polymers. It further expanded on the current commonly used plasticizers and highlighted the demerits in the use of these plasticizers. It introduced bioplasticizers and describe the current drift of the plasticizer to biobased ones. Potential biomass sources for the production of bioplasticizers were analyzed as well. With citrate plasticizer as one of the productive emerging plasticizers, its production, legal uses, effects and advantages were explored as well. Graphs and data exploring the future of bioplasticizers as worthwhile investment were discussed as well.

\subsection{REFERENCES}

Grand View Research, Bio-Plasticizers Market - Market Estimates \& Trend Analysis, (2017) 1-44.

[2] O. Yesid, Encyclopedia of Polymers and Composites, Encycl. Polym. Compos. (2014). https://doi.org/10.1007/978-3-64237179-0.

[3] T. Mekonnen, P. Mussone, H. Khalil, D. Bressler, Progress in bio-based plastics and plasticizing modifications, J. Mater. Chem. 

X.-F. Wei, E. Linde, M.S. Hedenqvist, Plasticiser loss from plastic or rubber products through diffusion and evaporation, $\mathrm{Npj}$ Mater. Degrad. 3 (2019). https://doi.org/10.1038/s41529-0190080-7.

[5] X.-F. Wei, K.J. Kallio, S. Bruder, M. Bellander, M.S. Hedenqvist, Plasticizer loss in a complex system (polyamide 12): Kinetics, prediction and its effects on mechanical properties, Polym. $\begin{array}{llll}\text { Degrad. } & \text { Stab. } & 169 & \text { (2019) } \\ & & \end{array}$ https://doi.org/10.1016/j.polymdegradstab.2019.108985.

[6] A.A. Ayamba, M. Ali, D. Carboo, F.J. Awuku, Extraction and Determination of Phthalates Content in Polyethylene Food Contact Materials on the Ghanaian Market, J. Nat. Sci. Res. 8 (2018) 1-6.

[7] A. Royaux, I. Fabre-Francke, N. Balcar, G. Barabant, C. Bollard, B. Lavédrine, S. Cantin, Aging of plasticized polyvinyl chloride in heritage collections: The impact of conditioning and cleaning treatments, Polym. Degrad. Stab. 137 (2017) 109-121. https://doi.org/10.1016/j.polymdegradstab.2017.01.011.

[8] E. Linde, U.W. Gedde, Plasticizer migration from PVC cable insulation - The challenges of extrapolation methods, Polym. Degrad. Stab. 101 (2014) 24-31. https://doi.org/10.1016/j.polymdegradstab.2014.01.021.

[9] R. Wolf, B.L. Kaul, Plastics, Additves, Ullmann's Encycl. Ind. Chem. (2012) 619-671. https://doi.org/10.1002/14356007.a20.

[10] Cabotcorp, Global demand for plasticizers continues to rise, (2017) 10-11. https://doi.org/10.1016/S0306-3747(17)30137-9.

[11] A.D. Godwin, Applied Plastics Engineering Handbook, Appl. Plast. Eng. Handb. (2011) 487-501. https://doi.org/10.1016/B978-1-4377-3514-7.10028-5.

[12] S. Varughese, D.K. Tripathy, Effect of Plasticizer Type and Concentration on the Dynamic Mechanical Properties of Epoxidized Natural Rubber Vulcanizates, J. Elastomers Plast. 25 (1993) 343-357. https://doi.org/10.1177/009524439302500405.

[13] E. Snejdrova, M. Dittrich, Pharmaceutical Applications of Plasticized Polymers, Recent Adv. Plast. (2012). https://doi.org/10.5772/36543.

[14] A.D. Godwin, Plasticizer selection for specific applications, Basic Chem. Intermed. Technol. (1933) 175157-75.

[15] A. Marcilla, M. Beltrán, Mechanisms of plasticizers action, Handb. Plast. Third Ed. (2017) 119-134. https://doi.org/10.1016/B978-1-895198-97-3.50007-X.

[16] B.P. Shtarkman, I.N. Razinskaya, Plasticization mechanism and structure of polymers, Acta Polym. 34 (1983) 514-520. https://doi.org/10.1002/actp.1983.010340812.

[17] V. Ambrogi, W. Brostow, C. Carfagna, M. Pannico, P. Persico, Plasticizer migration from cross-linked flexible PVC: Effects on tribology and hardness, Polym. Eng. Sci. (2012). https://doi.org/10.1002/pen.22070.

[18] K. McCormick, N. Kautto, The Bioeconomy in Europe: An Overview, Sustain. 5 (2013) 2589-2608. https://doi.org/10.3390/su5062589.

[19] Y. Zhang, J.H. Han, Plasticization of pea starch films with monosaccharides and polyols, J. Food Sci. 71 (2006) 253-261. https://doi.org/10.1111/j.1750-3841.2006.00075.x.

[20] M.G.A. Vieira, M.A. Da Silva, L.O. Dos Santos, M.M. Beppu, Natural-based plasticizers and biopolymer films: A review, Eur. $\begin{array}{lllll}\text { Polym. } & \text { J. } & 47 & \text { (2011) } & \text { 254-263. }\end{array}$ https://doi.org/10.1016/j.eurpolymj.2010.12.011.

[21] M.A.R. Meier, J.O. Metzger, U.S. Schubert, Plant oil renewable resources as green alternatives in polymer science, Chem. Soc. Rev. 36 (2007) 1788-1802. https://doi.org/10.1039/b703294c.

[22] M. Bocqué, C. Voirin, V. Lapinte, S. Caillol, J.J. Robin, Petrobased and bio-based plasticizers: Chemical structures to plasticizing properties, J. Polym. Sci. Part A Polym. Chem. 54 (2016) 11-33. https://doi.org/10.1002/pola.27917

[23] Satriana, N. Arpi, Y.M. Lubis, Adisalamun, M.D. Supardan, W.A.W. Mustapha, Diacylglycerol-enriched oil production using chemical glycerolysis, Eur. J. Lipid Sci. Technol. (2016). https://doi.org/10.1002/ejlt.201500489.

[24] M.T. Rodríguez, S.J. García, R. Cabello, J.J. Suay, J.J. Gracenea, Effect of plasticizer on the thermal, mechanical, and anticorrosion properties of an epoxy primer, J. Coatings Technol. Res. 2 (2005) 557-564. https://doi.org/10.1007/s11998-0050015-9.
[25] P. Jia, H. Xia, K. Tang, Y. Zhou, Plasticizers derived from biomass resources: A short review, Polymers (Basel). 10 (2018). https://doi.org/10.3390/polym10121303.

[26] Z. Yang, H. Peng, W. Wang, T. Liu, Crystallization behavior of poly( $\varepsilon$-caprolactone)/layered double hydroxide nanocomposites, J. Appl. Polym. Sci. $116 \quad$ (2010) 2658-2667. https://doi.org/10.1002/app.

[27] RSC, Chemistry for Biologists: Carbohydrates, Chem. Biol. (2019).

[28] B. Adhikari, D.S. Chaudhary, E. Clerfeuille, Effect of plasticizer on the moisture migration behavior of low-amylose starch films during drying, Dry. Technol. 28 (2010) 468-480. https://doi.org/10.1080/07373931003613593.

[29] H.R.E. Kaspar, A. Pizzi, Industrial plasticizing/dispersion aids for cement based on polyflavonoid tannins, J. Appl. Polym. Sci. 59 (1996) 1181-1190. https://doi.org/10.1002/(SICI)10974628(19960214)59:7<1181::AID-APP16>3.0.CO;2-8

[30] H.M. Shaikh, K. V. Pandare, G. Nair, A.J. Varma, Utilization of sugarcane bagasse cellulose for producing cellulose acetates: Novel use of residual hemicellulose as plasticizer, Carbohydr.
Polym.
(2009)
$23-29$. https://doi.org/10.1016/j.carbpol.2008.09.014.

[31] E. Azwar, B. Yin, M. Hakkarainen, Liquefied biomass derived plasticizer for polylactide, J. Chem. Technol. Biotechnol. 88 (2013) 897-903. https://doi.org/10.1002/jctb.3918.

[32] P.Y. Mikus, S. Alix, J. Soulestin, M.F. Lacrampe, P. Krawczak X. Coqueret, P. Dole, Deformation mechanisms of plasticized starch materials, Carbohydr. Polym. 114 (2014) 450-457. https://doi.org/10.1016/j.carbpol.2014.06.087

[33] A. Greco, D. Brunetti, G. Renna, G. Mele, A. Maffezzoli, Plasticizer for poly(vinyl chloride) from cardanol as a renewable resource material, Polym. Degrad. Stab. 95 (2010) 2169-2174. https://doi.org/10.1016/j.polymdegradstab.2010.06.001.

[34] R.E. Culea, R.M. Tamba-Berehoiu, N.C. Popa, SENSORY PROPERTIES OF SOME WHITE WINES, FLAVORED WINES AND VERMOUTH TYPE WINES, PREPARED BY USING OWN RECIPES, Sci. Pap. Manag. Econ. Eng. Agric. Rural Dev. (2015)

[35] H. Yang, H. Song, H. Zhang, P. Chen, Z. Zhao, Esterification of citric acid with n-butanol over zirconium sulfate supported on molecular sieves, J. Mol. Catal. A Chem. 381 (2014) 54-60. https://doi.org/10.1016/j.molcata.2013.10.001

[36] J.W. Gooch, Triethyl Citrate, Encycl. Dict. Polym. (2011) 765 765. https://doi.org/10.1007/978-1-4419-6247-8_12113.

[37] D.J. Rowe, Chemistry and Technology of Flavours and Fragrances, Blackwell Publ. Ltd. 1 (2005) 53.

[38] P. WU, Z. WANG, Y. CHEN, CN104945257 (A) - Method for preparing triethyl citrate, GUANGDONG HEC Pharm. CO. LTD,. (2015) 3.

[39] K.Y. Nandiwale, S.P. Borikar, V. V. Bokade, Synthesis of NonToxic Triethyl Citrate Plasticizer by Esterification of Renewable Citric Acid Using Modified Zeolite, 33 (2011) 1-47.

[40] Market and Market, Plasticizers Market - Trends and Forecasts to 2019, 5699 (2013)

[41] Polaris Research, GLOBAL BIO-PLASTICIZERS MARKET, (2015).

[42] Cerena, Ceresana's latest report details growth and change for global plasticizers market, Addit. Polym. 2019 (2019) 11. https://doi.org/10.1016/s0306-3747(19)30137-x

[43] G. Wypych, Plasticizer types, Handb. Plast. Third Ed. ChemTec $\mathrm{Pu}$ (2017) 7-84. https://doi.org/10.1016/B978-1-895198-97 $3.50004-4$

\section{LIST OF FIGURES}

Figure 1: Illustration of the role of a plasticizer in a polymer matrix

Figure 2: A graph showing the global plasticizer volume from $2014-2020$.

Figure 3: A graph showing the regional distributional of

plasticizer consumption ................................................. 2

Figure 4: Theories of plasticization..................................... 3

Figure 5: Biomass sources for bioplasticizers ......................... 3

Figure 6: Chemical structure of triethyl acetate ..................5 
Figure 7: Global bioplasticizers market by worth and volume from 2016 - 2025 ...........................................5

Figure 8: Bio plasticizer market revenue distribution by product: A case study in US

\section{LIST OF TABLES}

Table 1: Industrial bio-plasticizers used in the Industry scale (Bocqué et al., 2016) .............................................3

Table 2: Comparison of bioplasticizers and their biomass sources.................................................................... 4

\section{LIST OF EQUATIONS}

Equation 1: Esterification of citric acid and ethyl alcohol. .4 